\title{
EXPERIMENTAL STUDY OF DYNAMIC EFFECTS IN MOISTURE TRANSFER IN BUILDING MATERIALS
}

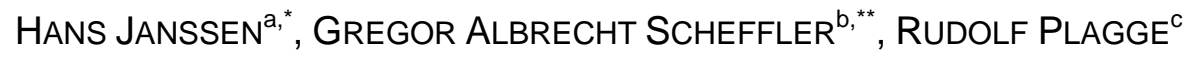 \\ a: Building Physics Section, Department of Civil Engineering, KU Leuven \\ $b$ : Section of Building Physics and Services, Department of Civil Engineering, \\ Technical University of Denmark \\ c: Institute of Building Climatology, Dresden University of Technology \\ *: $\quad$ corresponding author, Kasteelpark Arenberg 40, 3000 Leuven, Belgium; \\ hans.janssen@bwk.kuleuven.be; +32 16321326 \\ **: $\quad$ currently at: Ingenieurbüro Dr. Scheffler \& Partner GmbH, Dresden, Germany
}

\begin{abstract}
In relation to moisture storage in porous materials, it is often assumed that the process dynamics do not affect the moisture retention. There is mounting evidence though that this notion is incorrect: various studies demonstrate that the moisture retention is influenced by the (de)saturation rates of the moisture transfer processes involved. The available evidence primarily stems from imbibition and drainage experiments on soils however, and compared to many other porous media, these tests consider rather permeable materials with relatively dominant liquid transport at comparatively large (de)saturation rates. The current knowledge may thus not be directly transferable to moisture transfer in porous media on the whole, and dedicated further research is required.

This paper responds to that need, by reporting on an experimental investigation of the occurrence of dynamic effects on moisture transfer in building materials. Drying and ad-/desorption tests are executed on two building materials, in which moisture contents and moisture potentials are measured simultaneously. These are translated into dynamic retention relations and dynamic storage coefficients, which both distinctly demonstrate that moisture transfer in building materials, similar to moisture transfer in soils, is not free of dynamic effects. The findings imply that the widely accepted static theory for moisture storage in porous media is not generally valid and should be corrected for the occurrences of dynamic effects. Considering that such drying and ad-/desorption processes are dominant features in very many instances of moisture transfer in porous media, the repercussions of these findings may be large.
\end{abstract}

\section{KEYWORDS}

moisture transfer; building materials; moisture storage; dynamic effects; drying, ad- and desorption; porous media

\section{HIGHLIGHTS}

- presently moisture storage in porous materials is assumed free of dynamic effects

- there is though mounting counterevidence for moisture transfer processes in soils

- here proof of dynamic effects for moisture transfer in building materials is brought

- via moisture content and potential measurement during drying and ad-/desorption

- drying and ad-/desorption are widely applied: findings' repercussions may be large 
Postprint: Janssen H, Scheffler GA, Plagge R. 2016. Experimental study of dynamic effects in moisture transfer in building materials, International Journal of Heat and Mass Transfer, 98: 141-149.

doi: 10.1016/j.ijheatmasstransfer.2016.03.031

\section{INTRODUCTION}

Moisture transfer in porous media is omnipresent: it takes place at the microscale of cement particle hydration [1] as well as at the macroscale of nuclear waste storage [2]. For very many disciplines hence, a proper understanding and reliable assessment of moisture transfer in porous media are crucial [3]-[10]. Also in the built environment, the transfers of moisture and all chemicals dissolved therein play a crucial role. Moisture transfer affects the durability and sustainability of built structures: the corrosion of reinforcement bars in concrete due to chloride ingress via the pore water is just one example of potential damage. Moisture transfer also influences the health and comfort of building occupants: excessive interior humidity levels induce mould formation or depreciate interior air quality. Moisture is for that reason often a critical factor when judging the durability and sustainability of built structures and the health and comfort of building occupants, and a reliable description of moisture transfer in building materials is hence crucial for correct assessments.

A core concept in any description of moisture transfer in porous materials is the 'moisture retention': the relation between the moisture potential and the moisture content. It is generally assumed that moisture retention relations determined from static experiments are applicable for transient conditions and vice versa. In other words, it is commonly accepted that the process dynamics do not affect the moisture potential-moisture content relation. In other words again, an immediate and universal equilibrium between moisture potential and moisture content is supposed. Currently although, ample evidence exists that this is not always valid: numerous experimental, theoretical and numerical studies [11]-[22] support that moisture retention is influenced by the (de)saturation rates of the moisture transfer processes involved, the so-called dynamic effects.

Most evidence on dynamic effects for moisture transfer in porous media stems from soil physics. The earliest confirmation on deviations between static and dynamic moisture retention relations was presented by Topp et al. [11] and Smiles et al. [12]: these authors demonstrated that imposing a higher desorption rate in outflow experiments results in increased deviations from the static moisture retention relations. While these authors limited the experiments to sandy soil with narrow pore size distribution during a drainage process, Wana-Etyem [13] arrived at parallel observations for fine- and coarse-textured soils for drainage and imbibition processes. Thorough reviews of the early and recent work respectively can be found in [14] and [15]-[16]. Much of the present research targets physical origins [17]-[18], mathematical models [19]-[20], and impact appraisals [14],[21]; see [14]-[16] for an overview again.

Virtually all of the currently available evidence on dynamic effects for moisture transfer stems from imbibition and drainage experiments on soils. With respect to many other porous media, these tests concern rather permeable materials with relatively dominant liquid transport at comparatively large (de)saturation rates. Generally though, moisture transfer in porous media - among which building materials - involves less permeable materials, with mixed liquidvapour transfer, at lower (de)saturation rates [3]-[8]. The present knowledge on dynamic effects may thus not be directly transferable to moisture transfer in porous media on the whole, and dedicated further research is consequently needed. This paper therefore documents an experimental investigation of the occurrence of dynamic effects on moisture transfer in building materials. The analysed drying and ad-/desorption processes are crucial features in very many instances of moisture transfer in porous media.

The paper is organised as follows. The next section puts forward measurement methods for the concurrent determination of moisture contents and moisture potentials during drying and ad- and desorption tests, as well as material properties for the calcium silicate board and the autoclaved aerated concrete that are measured on. The outcomes of the experiments are illustrated in a following section, clearly demonstrating deviations between static and dynamic moisture retention relations, leading to dynamic storage coefficients $\mathrm{T}$ of $10^{12}$ to $10^{14} \mathrm{~kg} /(\mathrm{m} \cdot \mathrm{s})$ and $10^{14}$ to $10^{16} \mathrm{~kg} /(\mathrm{m} \cdot \mathrm{s})$ for drying and ad-/desorption respectively. In the discussion, these outcomes are further interpreted and put into larger perspective via a comparison with literature results on dynamic effects in moisture transfer in porous media. The conclusions lastly summarise our findings. 
Postprint: Janssen H, Scheffler GA, Plagge R. 2016. Experimental study of dynamic effects in moisture transfer in building materials, International Journal of Heat and Mass Transfer, 98: 141-149.

\section{MATERIALS AND METHODS}

The experimental program of the study comprises drying and ad-/desorption measurements, on calcium silicate board and autoclaved aerated concrete, wherein moisture potentials and moisture contents are measured simultaneously at multiple locations in the sample. After the smoothing of the moisture content values, the data are translated to dynamic retention relations and dynamic storage coefficients, for the qualitative and quantitative interpretation of the dynamic effects.

\subsection{Materials}

Two typical building materials are used: calcium silicate board (CaSi), a capillary active interior insulation material, and autoclaved aerated concrete (AAC), an insulating building block. Both materials are manufactured by well-defined production processes, leading to highly homogeneous material samples. The full hygric characterisation of these two materials stems from [22], an overview of their basic properties is given in Table 1. Static moisture retention relations - reference for our interpretation of the dynamic relations - are obtained with steady-state tests: desiccator measurements over oversaturated salt solutions for the adsorption moisture retention and pressure plate experiments combined with desiccator measurements for the desorption moisture retention.

Table 1: Basic material properties for calcium silicate board and autoclaved aerated concrete

\begin{tabular}{|l|c|c|}
\hline & calcium silicate board & autocl. aerat. concrete \\
\hline bulk density $\left[\mathrm{kg} / \mathrm{m}^{3}\right]$ & 280 & 400 \\
\hline saturated moisture content $\left[\mathrm{kg} / \mathrm{m}^{3}\right]$ & 910 & 700 \\
\hline capillary moisture content $\left[\mathrm{kg} / \mathrm{m}^{3}\right]$ & 880 & 275 \\
\hline capillary absorption coeff. $\left[\mathrm{kg} /\left(\mathrm{m}^{2} \mathrm{~s}^{0.5}\right]\right.$ & 1.11 & 0.043 \\
\hline moisture content at $85 \% \mathrm{RH}\left[\mathrm{kg} / \mathrm{m}^{3}\right]$ & 6 & 23 \\
\hline vapour resistance factor $[-]$ & 4.0 & 7.5 \\
\hline
\end{tabular}

\subsection{Experiments}

\subsubsection{Drying tests}

A sample is brought to its capillary moisture content with a free water uptake test, and is then exposed to a drying environment with its bottom surface. During the test the X-ray projection method is applied for moisture content determination while thermocouple psychrometers and capacitive relative-humidity sensors are used for moisture potential measurement. Measurements are executed with the equipment at the Department of Civil Engineering at the Technical University of Denmark [23].

A schematic and photographs of the set-up can be found in Figure 1. The material sample is $40 \times 160 \times 80 \mathrm{~mm}^{3}(\mathrm{~h} \times \mathrm{w} \times \mathrm{d})$. Its lateral surfaces are sealed by gluing thin acrylic glass sheets to the surfaces; its top face is simply covered, with perforations to allow air pressure equilibration. A part of the front face is outfitted with an acrylic glass stencil, comprising four predrilled and threaded holes, in sets of two at $10 \mathrm{~mm}$ and at $17 \mathrm{~mm}$ above the bottom surface. These stencils guide the drilling of $25 \mathrm{~mm}$ deep and $5 \mathrm{~mm}$ diameter holes in the samples and moreover act as receptors for the measurement sensors to be installed. One Wescor thermocouple psychrometer and one Ahlborn combined temperature and humidity probe are inserted at each height, and these are respectively connected to a Wescor Psypro control system and a Ahlborn Almemo 2890-9 datalogger. The high relative humidity values - over $96 \% \mathrm{RH}-$ are measured every 30 minutes with the psychrometers, while the lower relative humidity values - below $98 \% \mathrm{RH}$ - are monitored with the humidity sensors every 15 minutes. Moisture contents are determined by use of X-ray projection [23]-[24], for which a GNI X-ray system is applied, comprising a $25 \times 25 \mathrm{~mm}^{2}$ detector. The complete set-up is hence constructed in the Xray chamber and the experiment is performed within that chamber. To avoid disturbance by the sensors present, the moisture contents are determined at the other end of the sample; to 
Postprint: Janssen H, Scheffler GA, Plagge R. 2016. Experimental study of dynamic effects in moisture transfer in building materials, International Journal of Heat and Mass Transfer, 98: 141-149.
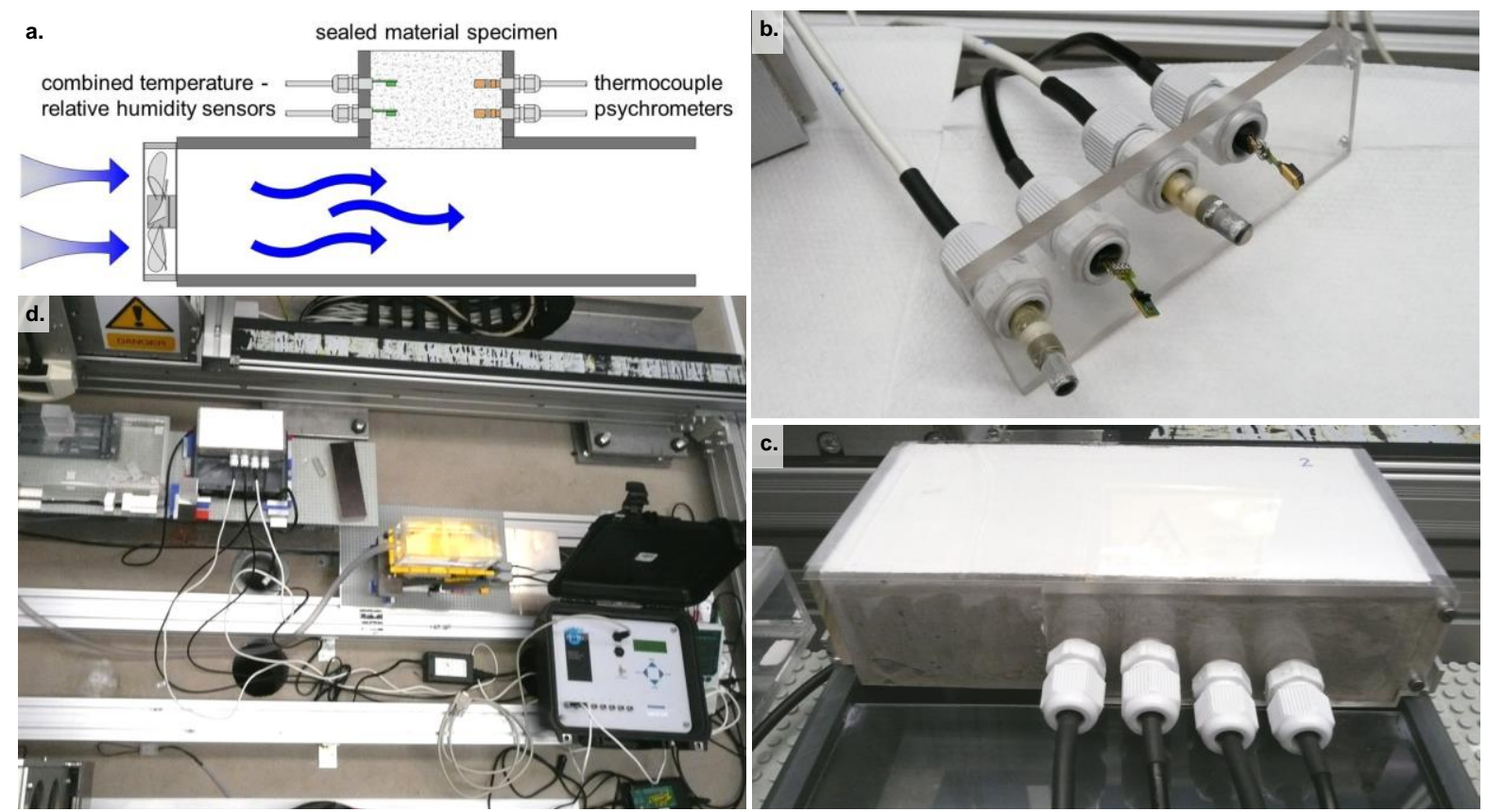

Figure 1: Scheme and photographs of the experimental set-up for the drying tests at Technical University of Denmark: a) schematic overview of set-up and sensors (in reality all sensors are at the same side) b) detail of the two psychrometers and two capacitive sensors, $c$ ) final sample fitted with sensors, d) global set-up in X-ray chamber.

preclude movement of the X-ray detector, moisture contents are only monitored for the lower $23 \mathrm{~mm}$ of the sample. Moisture contents are registered at gradually increasing time intervals, ranging from $0.5 \mathrm{~h}$ to $4 \mathrm{~h}$ for $\mathrm{CaSi}$ and from $0.5 \mathrm{~h}$ to $6 \mathrm{~h}$ for AAC.

The accuracy of the X-ray measurements is assessed based on [24], and a resolution of well below $1 \mathrm{~kg} / \mathrm{m}^{3}$ is obtained. The thermocouple psychrometers are calibrated over unsaturated salt solutions ( 96.70 to $99.98 \% \mathrm{RH})$, yielding an absolute accuracy below $0.1 \%$. The capacitive relative-humidity sensors are new, and stated to have an absolute accuracy of $\pm 0.8 \%$ after the producer's calibration, which is verified over oversaturated salt solutions (11.3 to 97.6 $\% \mathrm{RH})$. Such accuracies are presumed sufficient for the moisture contents and relative humidities expected during the drying tests.

After preconditioning to capillary moisture content, the drying test is started by exposing the sample's lower surface to a drying environment, wherein X-ray chamber air - with temperature around $23{ }^{\circ} \mathrm{C}$ and relative humidity around $35 \%$ - is driven over the surface with small fans. These fans procure fully mixed conditions and relatively high surface transfer coefficients at the drying surface of the sample.

\subsubsection{Ad-/desorption tests}

For adsorption, a sample is preconditioned in a desiccator at low relative humidity, and is exposed to a high relative humidity environment with its bottom surface. For desorption the reverse procedure is applied. During the test time-domain reflectometry is applied for moisture content determination while capacitive relative-humidity sensors are used for moisture potential measurement. Measurements are executed with the equipment from the Institute of Building Climatology at the Dresden University of Technology [25].

A schematic and an illustration of the set-up can be retrieved in Figure 2. The material sample is $100 \times 100 \times 50 \mathrm{~mm}^{3}(\mathrm{~h} \times \mathrm{w} \times \mathrm{d})$, which is sealed similarly to the drying samples above. Two templates in acrylic glass are mounted: one on the side surface, one on part of the front surface. They hold five prefitted guide bolts each, serving again as drilling guidance and probe receptor, located at 10, 30, 50, 70 and $90 \mathrm{~mm}$ above the bottom surface. Ahlborn combined temperature and humidity probes are inserted at the front, in predrilled holes with diameter 4 $\mathrm{mm}$ and depth $30 \mathrm{~mm}$, measuring the relative humidity every 10 minutes. Moisture contents 
Postprint: Janssen H, Scheffler GA, Plagge R. 2016. Experimental study of dynamic effects in moisture transfer in building materials, International Journal of Heat and Mass Transfer, 98: 141-149.
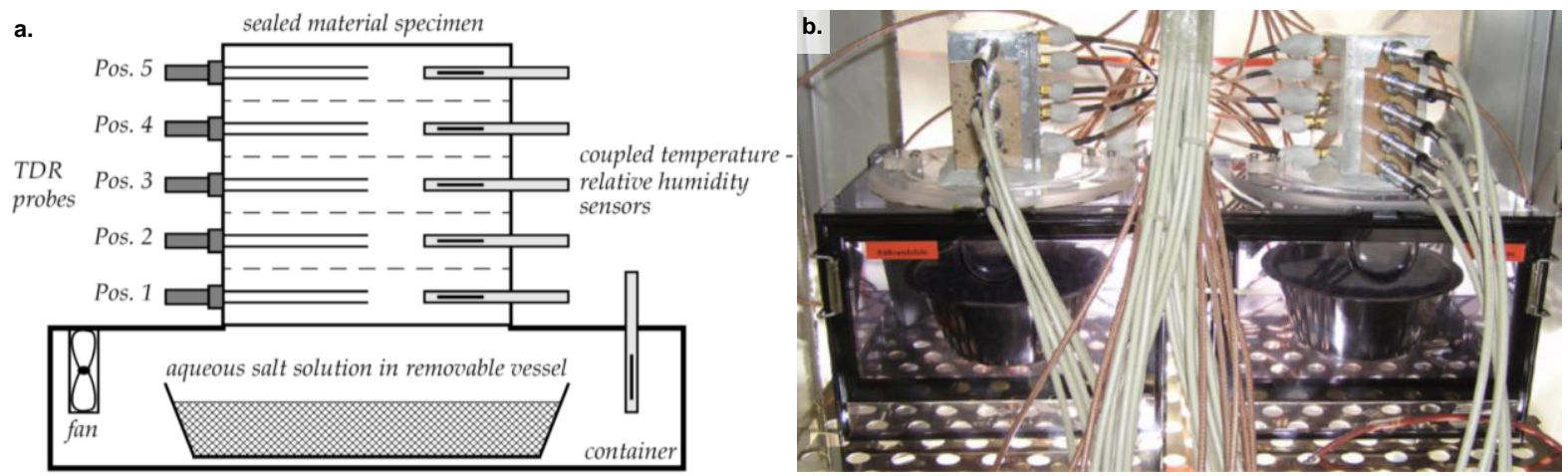

Figure 2: Scheme and photograph of the experimental set-up for the adsorption tests at Dresden University of Technology: a) schematic overview of set-up and sensors, b) final sample fitted with sensors, on top of the small climate chamber.

are determined every 20 minutes, with miniaturised time-domain-reflectometry probes (an inhouse design of Institute of Agrophysics, Lublin [26]-[27]), inserted at the side by gently pressing the two $6-\mathrm{cm}$ long needles into the material. Proper calibration of the sensors [25] gives accuracies of respectively $0.5 \% \mathrm{RH}$ and $0.2 \mathrm{~kg} / \mathrm{m}^{3}$.

After preconditioning to $22.5{ }^{\circ} \mathrm{C}$ and $33 \% \mathrm{RH}$, the adsorption test is initiated by exposing the sample's lower surface to a $22.5^{\circ} \mathrm{C}$ and $97 \% \mathrm{RH}$ environment, established by a small climate-controlled box, where a small fan with external motor maintains fully mixed conditions and high surface transfer coefficients. The desorption test exposes the sample's lower surface to a $22.5{ }^{\circ} \mathrm{C}$ and $33 \% \mathrm{RH}$ environment after preconditioning to $22.5^{\circ} \mathrm{C}$ and $97 \% \mathrm{RH}$.

\subsection{Processing}

Concurrent values of local moisture contents and moisture potentials are combined to obtain dynamic moisture retention relations, to be confronted to their static counterparts. The differences between the dynamic and static moisture retention relations are subsequently processed into dynamic storage coefficients, defined as [14]:

$$
\tau=\frac{\mathbf{p}_{\mathrm{c}}^{\text {dyn }}(\mathrm{S})-\mathbf{p}_{\mathrm{c}}^{\text {stat }}(\mathrm{S})}{\frac{\partial \mathrm{S}}{\partial \mathrm{t}}}=\frac{\mathbf{p}_{\mathrm{c}}^{\text {dyn }}(\mathbf{w})-\mathbf{p}_{\mathrm{c}}^{\text {stat }}(\mathbf{w})}{\frac{1}{\rho_{\ell} \Psi} \frac{\partial \mathrm{w}}{\partial \mathrm{t}}}
$$

where $\mathrm{T}[\mathrm{kg} /(\mathrm{m} \cdot \mathrm{s})]$ is the dynamic storage coefficient, $\mathrm{p}_{\mathrm{c}}{ }^{\text {dyn }}[\mathrm{Pa}]$ the dynamic capillary pressure, $p_{c}{ }^{\text {stat }}[\mathrm{Pa}]$ the static capillary pressure, $\mathrm{S}[-]$ the saturation, $\mathrm{t}[\mathrm{s}]$ the time, $\mathrm{w}\left[\mathrm{kg} / \mathrm{m}^{3}\right]$ the moisture content, $\rho_{\ell}\left[\mathrm{kg} / \mathrm{m}^{3}\right]$ the density of water and $\psi[-]$ is the porosity. Coefficient $\mathrm{T}$ hence quantifies the impacts of (de)saturation on the differences between dynamic and static moisture retention.

While the measurements of moisture potential generally yield smooth and stable results, the moisture content results are often marred by oscillations and scatter. The measured relative humidities are hence used directly, and their transformation to capillary pressures is attained via Kelvin's law. The measured moisture contents, on the other hand, are first put through a LOESS smoothing [28]-[30], thus reducing the potential disturbance of the dynamic moisture retention relations and dynamic storage coefficients. The (de)saturation rate - the time derivative of the moisture content in Equation (1) - is finally obtained via a central difference between the time points just after and just before the time point considered. 
Postprint: Janssen H, Scheffler GA, Plagge R. 2016. Experimental study of dynamic effects in moisture transfer in building materials, International Journal of Heat and Mass Transfer, 98: 141-149.

doi: 10.1016/j.ijheatmasstransfer.2016.03.031

\section{RESULTS}

\subsection{Drying}

\subsubsection{Raw data}

The drying tests last $160 \mathrm{~h}$, for both CaSi and AAC. At that moment the drying is well into its second drying phase, and continuation till equilibrium is deemed unnecessary, since the lesser desaturation rates nullify the potential dynamic effects. Moisture potentials - relative humidities measured by thermocouple psychrometers and capacitive sensors at the two measurement locations - are obtained every half hour. Moisture contents - determined via X-ray projection over the lower $23 \mathrm{~mm}$ of the sample - are registered at intervals growing from 0.5 $\mathrm{h}$ to $4 \mathrm{~h}$ and $6 \mathrm{~h}$ for $\mathrm{CaSi}$ and $\mathrm{AAC}$ respectively, giving $50 \mathrm{CaSi}$ and $38 \mathrm{AAC}$ data sets. They are translated into moisture mass integrals over the bottom $20 \mathrm{~mm}$ of the samples as well as local moisture contents at the two measurement locations. For the latter, the average over a $2 \mathrm{~mm}$ interval around the location is used, considering the size of the humidity sensors. The local moisture contents are finally put through a 7-point LOESS smoothing for stabilisation. The results are collected in Figures 3 and 4, for CaSi and AAC respectively. The local moisture contents and moisture mass integral for $\mathrm{CaSi}$ (Figure $3 a-b)$ point to a lengthy first drying phase: the second drying phase starts at around $100 \mathrm{~h}$. For AAC on the other hand, a minor first drying phase is noted (Figure 4a-b): the second phase already kicks in after $10 \mathrm{~h}$. Local relative humidities are measured twofold: with thermocouple psychrometers above $96 \% \mathrm{RH}$, with capacitive sensors below $98 \% \mathrm{RH}$. Final values are obtained by combining the two signals: early in the test, the (higher) relative humidities are taken from the psychrometers, and later in the test, the (lower) relative humidities are taken from the capacitive sensors. The results in Figures 3c-d and 4c-d show that the two sensor outcomes virtually coincide between 96 and $98 \% \mathrm{RH}$, confirming the reliability of the moisture potential measurements.
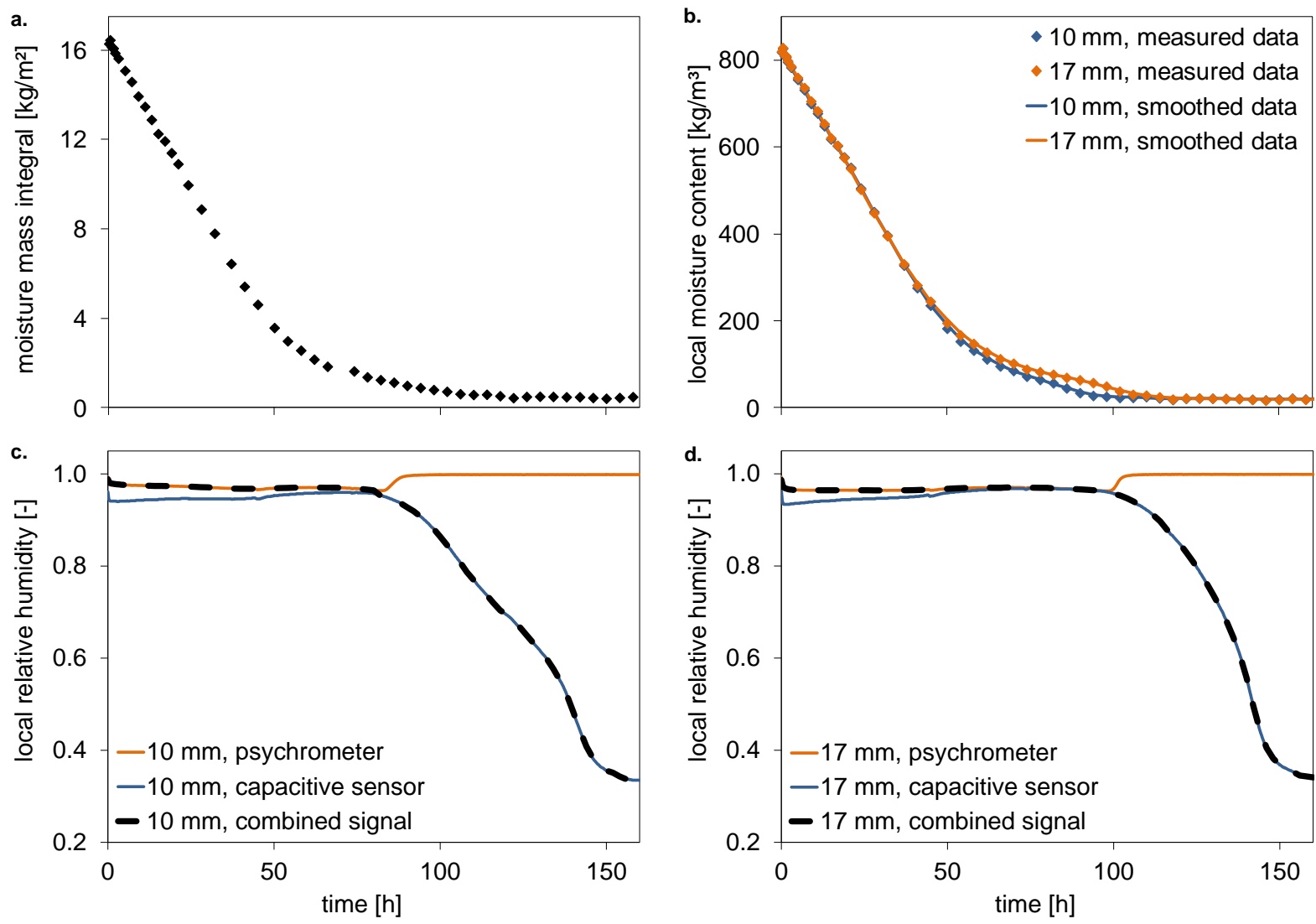

Figure 3: Raw data for the drying test on CaSi: a) moisture mass integral for bottom $20 \mathrm{~mm}$,

b) local moisture contents at measurement locations, c) local relative humidity at the $10 \mathrm{~mm}$ measurement location, d) local relative humidity at the $17 \mathrm{~mm}$ measurement location. 
Postprint: Janssen H, Scheffler GA, Plagge R. 2016. Experimental study of dynamic effects in moisture transfer in building materials, International Journal of Heat and Mass Transfer, 98: 141-149.
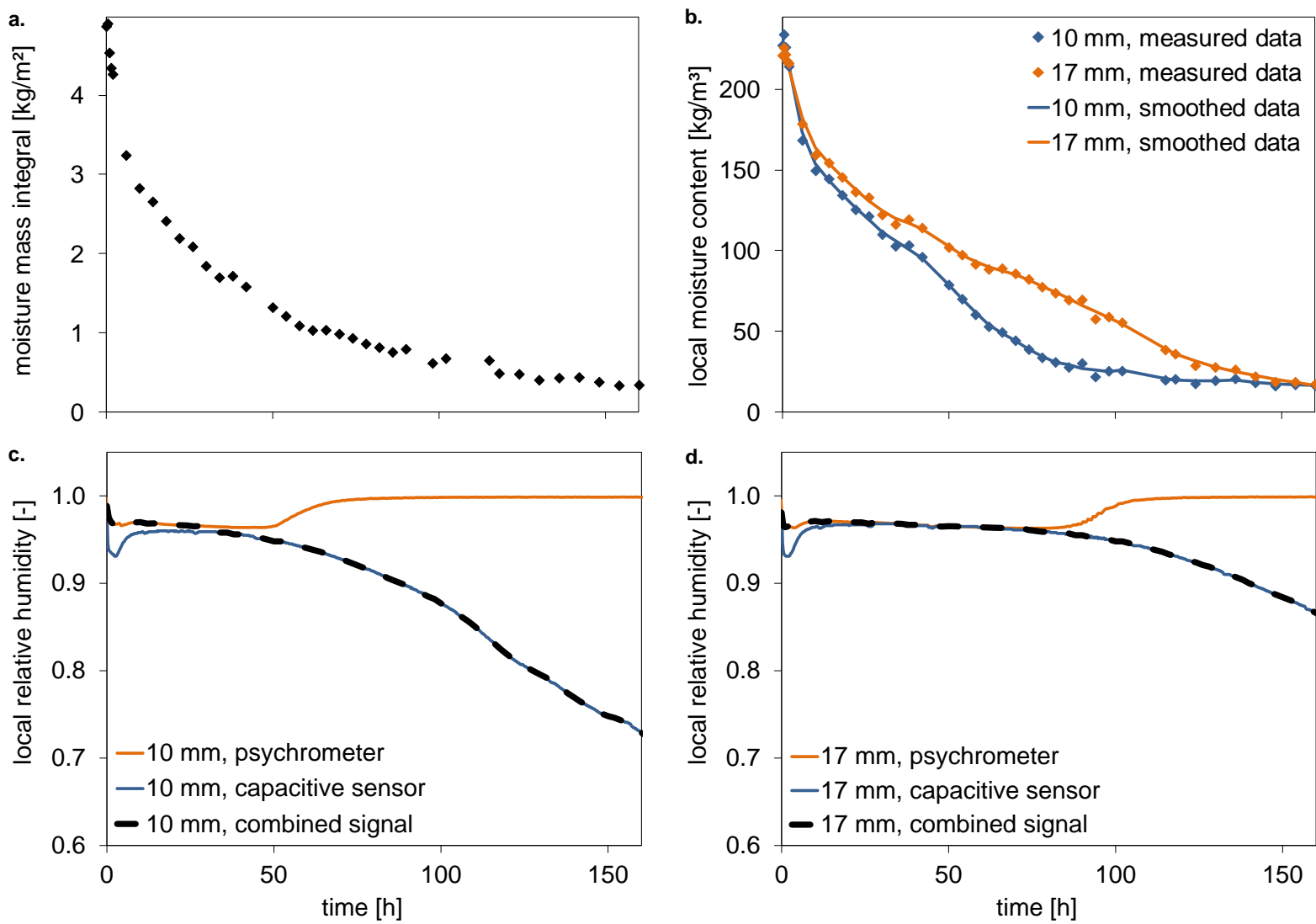

Figure 4: Raw data for the drying test on AAC: a) moisture mass integral for bottom $20 \mathrm{~mm}$,

b) local moisture contents at measurement locations, c) local relative humidity at the $10 \mathrm{~mm}$ measurement location, d) local relative humidity at the $17 \mathrm{~mm}$ measurement location.

\subsubsection{Processed outcomes}

Concurrent couples of moisture content and moisture potential are used to come to dynamic moisture retention relations, which are compared to their static relations in Figures $5 \mathrm{a}$ and $6 \mathrm{a}$ for $\mathrm{CaSi}$ and $\mathrm{AAC}$ respectively. Figures $5 \mathrm{~b}$ and $6 \mathrm{~b}$ show the dynamic storage coefficients, in function of the moisture content at which they were obtained. It is apparent that the dynamic moisture retention relations do not match with the static ones, a key indication of dynamic effects. For the two materials, the dynamic storage coefficients are in the $10^{12}$ to $10^{14} \mathrm{~kg} /(\mathrm{m} \cdot \mathrm{s})$ range, with no significant differences between the two measurement positions.
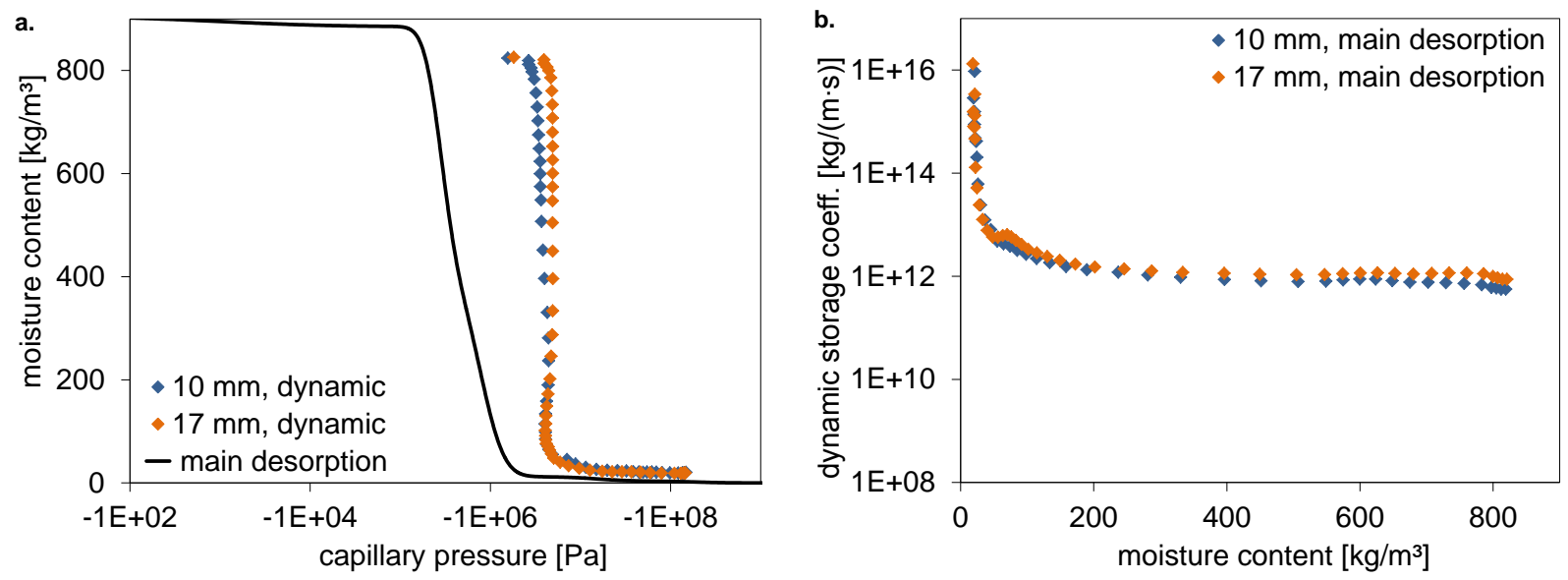

Figure 5: Processed outcomes for the drying test on CaSi: a) comparison of dynamic and static moisture retention relations, b) dynamic storage coefficients based on the main desorption curve. 
Postprint: Janssen H, Scheffler GA, Plagge R. 2016. Experimental study of dynamic effects in moisture transfer in building materials, International Journal of Heat and Mass Transfer, 98: 141-149.
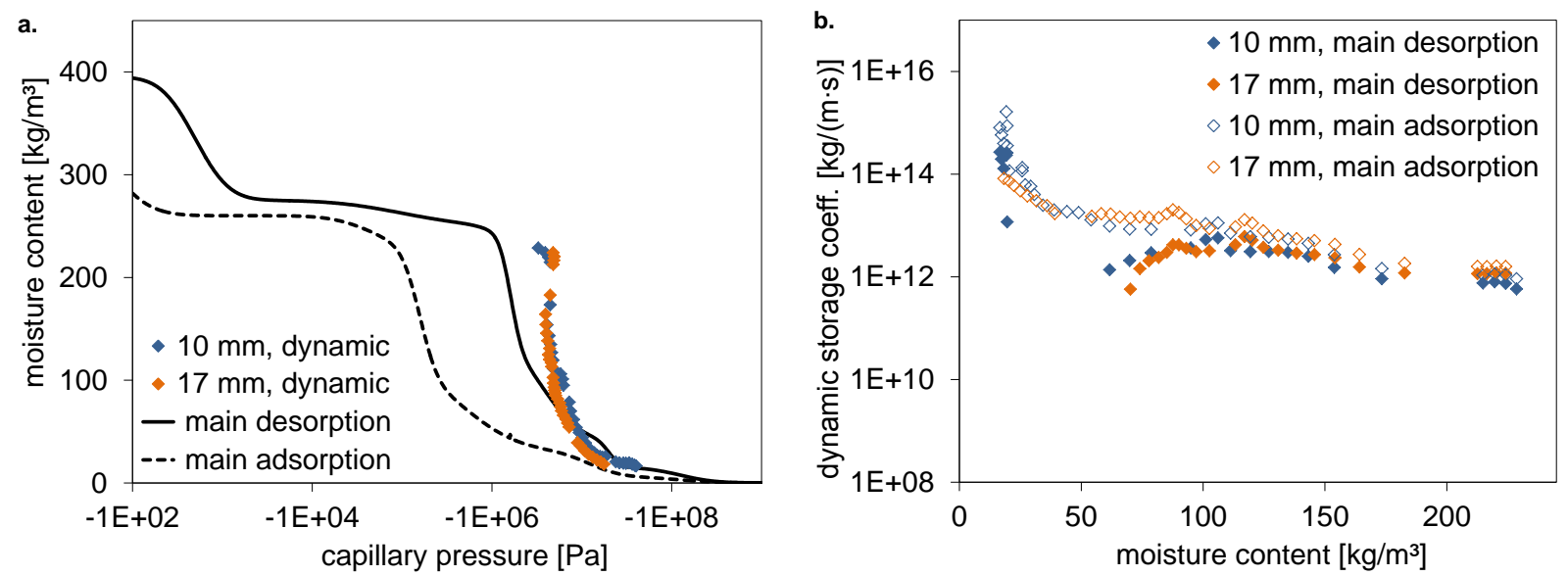

Figure 6: Processed outcomes for the drying test on AAC: a) comparison of dynamic and static moisture retention relations, b) dynamic storage coefficients based on the main desorption and the main adsorption curve.

Two comments are necessary here. Firstly, the dynamic storage coefficients at the smallest moisture contents (below $50 \mathrm{~kg} / \mathrm{m}^{3}$ for CaSi, below $20 \mathrm{~kg} / \mathrm{m}^{3}$ for AAC) stem from rather small desaturation rates, and should hence be interpreted with caution. Secondly, the initial conditioning to capillary moisture content via free water uptake implies that the primary desorption curve should be used as static moisture retention relation. Since this is unavailable, the main desorption curve has been applied instead. This simplification is expected to have almost no impact for CaSi: its small difference between saturated and capillary moisture content (Table 1) and its monomodal pore system (Figure 5a) should give very similar main and primary desorption curves. That is not the case though for AAC, which has a larger difference between saturated and capillary moisture content (Table 1) and a multimodal pore system (Figure 6a): more substantial differences between main and primary desorption curve are therefore likely. The consequence thereof is shown in Figure 6a-b: the dynamic and static moisture retention relations traverse in the 20 to $60 \mathrm{~kg} / \mathrm{m}^{3}$ range, with resultantly no t values in this interval. The true impact of the simplification should not be overrated though: calculating the dynamic storage coefficients with the main adsorption retention curve - an extreme option, given that the primary desorption curve takes a more intermediate position - yields a small rise of the $\mathrm{T}$ values, without affecting the order of magnitude however. The two sets of dynamic storage coefficients presented in Figure $6 \mathrm{~b}$ are thus to be considered the boundary curves, wherein the actual $\mathrm{t}$ values are to be assumed located. Given their similar order of magnitude, a reliable result is still obtained.

\subsection{Adsorption}

\subsubsection{Raw data}

The CaSi adsorption test and the AAC desorption test take respectively $408 \mathrm{~h}$ and $480 \mathrm{~h}$ : the ad-/desorption is still ongoing at that moment, but saturation/desaturation rates have reduced sufficiently to nullify dynamic effects. Moisture potentials are obtained at 10-minute intervals via capacitive relative-humidity sensors, moisture contents at 20 -minute intervals via time-domain reflectometry. A rougher temporal grid is superimposed to get a reduced data-set, with time intervals rising from $10 \mathrm{~min}$ to $24 \mathrm{~h}$, yielding 54 sets of moisture contents and potentials. While the retained moisture potentials are employed directly, the moisture contents are firstly put trough a 12-point LOESS smoothing, where the logarithm of time is used, as this yields a better fit near the time origin.

The results are collected in Figures 7 and 8, for CaSi and AAC respectively. The typical adand desorption behaviour is obtained: a rapid initial response of both relative humidities and moisture contents, which dampen with the time passed and with the distance from the exposed surface. At the end of the tests, the relative humidities are approaching their equilibrium values, while the moisture contents are still (slowly) evolving to the corresponding values. It 
Postprint: Janssen H, Scheffler GA, Plagge R. 2016. Experimental study of dynamic effects in moisture transfer in building materials, International Journal of Heat and Mass Transfer, 98: 141-149.

doi: 10.1016/j.jjheatmasstransfer.2016.03.031
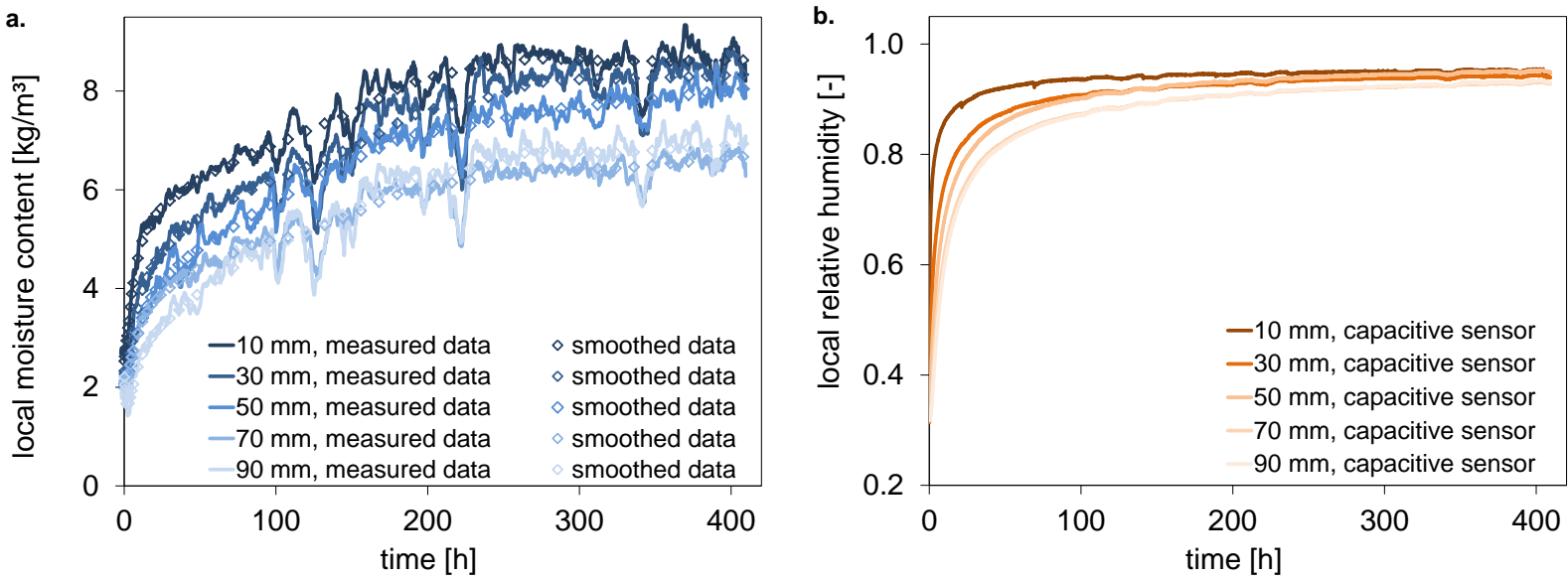

Figure 7: Raw data for the adsorption test on CaSi: a) local moisture contents at measurement locations, b) local relative humidities at measurement locations.
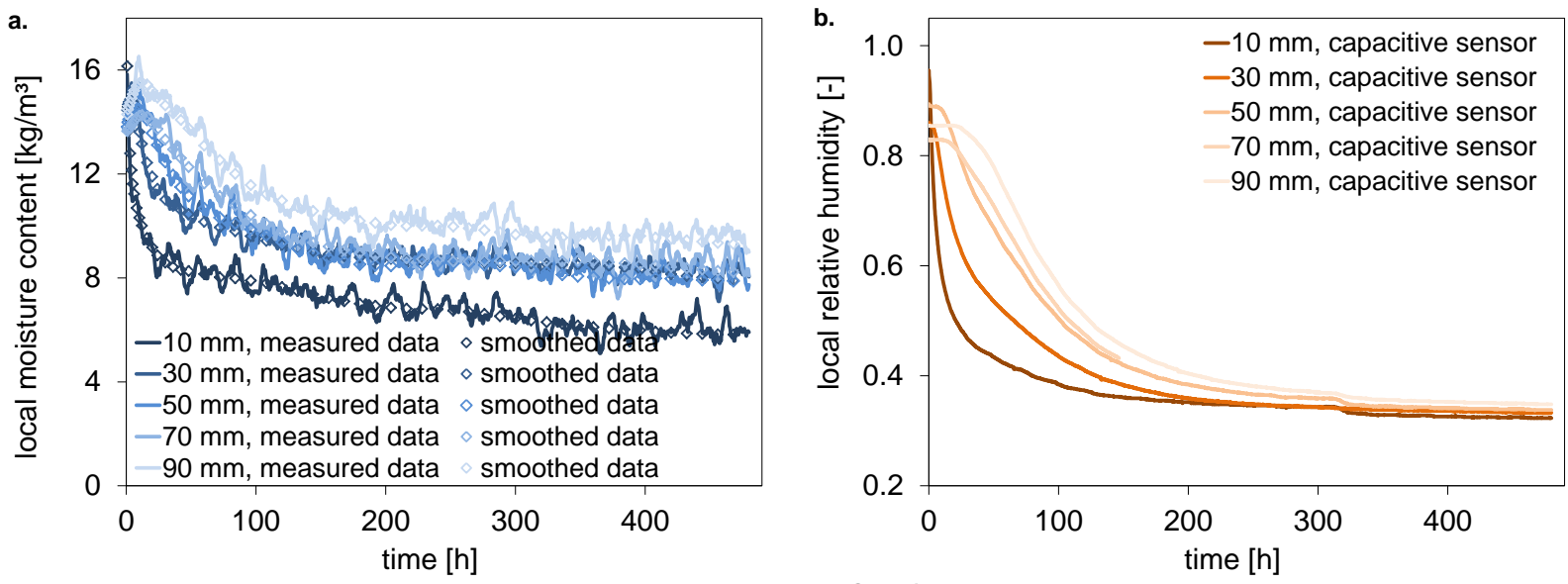

Figure 8: Raw data for the desorption test on AAC: a) local moisture contents at measurement locations, b) local relative humidities at measurement locations.

is clear from Figure 8 that the adsorption preconditioning of the AAC has not been allowed a sufficient amount of time: one expects relative humidities of $97 \%$ and corresponding moisture contents of around $32 \mathrm{~kg} / \mathrm{m}^{3}$, instead we find moisture contents of around $16 \mathrm{~kg} / \mathrm{m}^{3}$ and an average relative humidity of around $90 \%$. Despite this incomplete preconditioning, the AAC desorption test still yields significant and dependable results.

\subsubsection{Processed outcomes}

The dynamic moisture retention relations and dynamic storage coefficients are depicted in Figures 9 and 10, for $\mathrm{CaSi}$ and $\mathrm{AAC}$ respectively. For reasons of clarity, solely the three lower positions at 10,30 and $50 \mathrm{~mm}$ are processed. It is clear that the dynamic moisture retention relations do not match with the static ones, a key indication of dynamic effects. For both materials, the dynamic storage coefficients are in the $10^{14}$ to $10^{17} \mathrm{~kg} /(\mathrm{m} \cdot \mathrm{s})$ range, with only limited differences between the three measurement positions.

Two comments are required here. The adsorption preconditioning of $\mathrm{CaSi}$ appears to deviate from the adsorption isotherm: while the measured relative humidities do indeed match the desired $33 \%$, the moisture contents of around $2 \mathrm{~kg} / \mathrm{m}^{3}$ are somewhat higher than the expected $1.6 \mathrm{~kg} / \mathrm{m}^{3}$, see Figure $9 \mathrm{a}$. This could imply a minor error in the measured adsorption isotherm or in the measured moisture contents. An exploratory correction would shift the dynamic storage factors to somewhat lower moisture contents and/or higher $\mathrm{T}$ values, without any substantial influence though. Secondly, the actual desorption of AAC implies that the primary desorption curve should be used as static moisture retention relation. Because this is not available, an estimate is made, based on published results for the hygroscopic hysteresis of 
Postprint: Janssen H, Scheffler GA, Plagge R. 2016. Experimental study of dynamic effects in moisture transfer in building materials, International Journal of Heat and Mass Transfer, 98: 141-149.
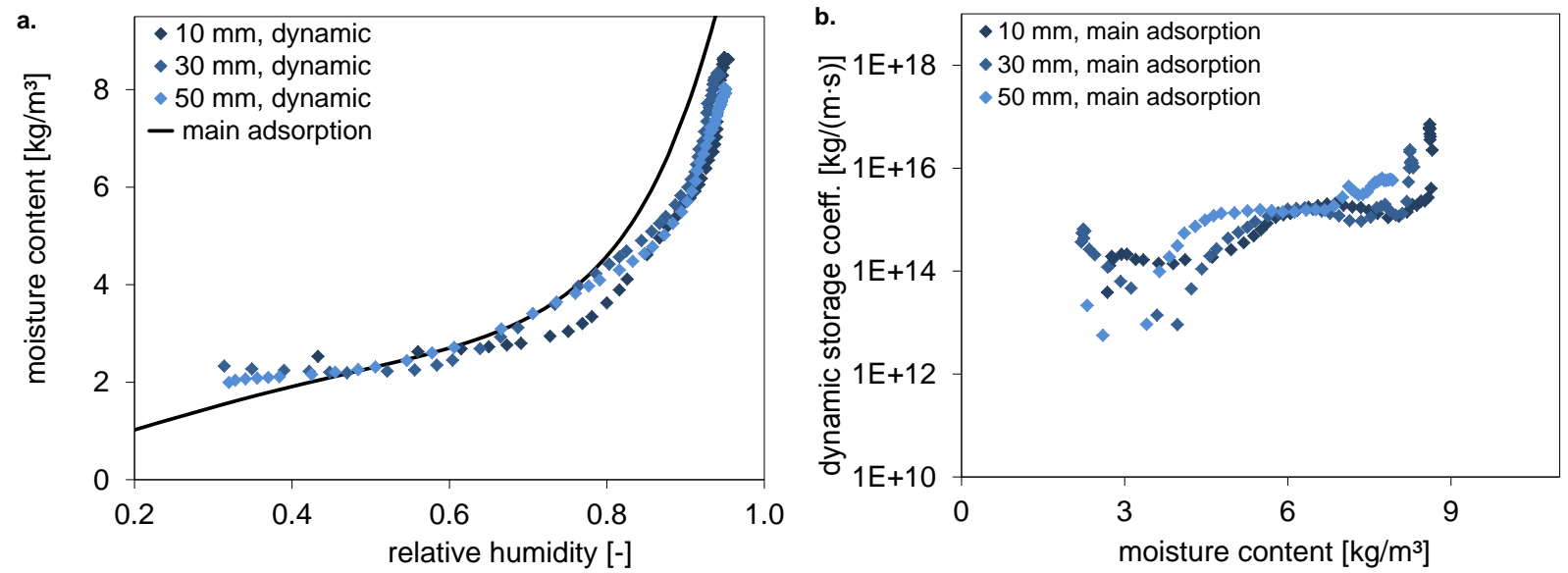

Figure 9: Processed outcomes for the adsorption test on CaSi: a) comparison of dynamic and static moisture retention relations, b) dynamic storage coefficients based on the main adsorption curve.
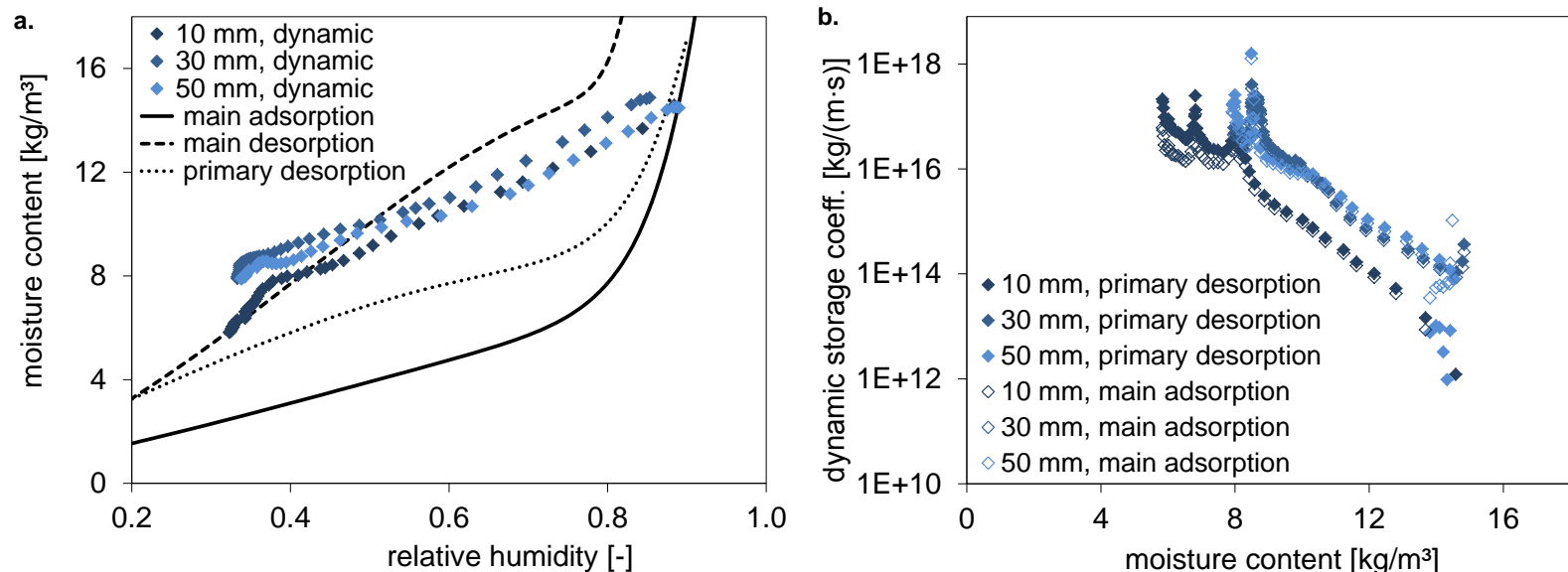

Figure 10: Processed outcomes for the desorption test on AAC: a) comparison of dynamic and static moisture retention relations, b) dynamic storage coefficients based on the primary desorption and main adsorption curve.

AAC [31]-[32], see Figure 10a. Given the incomplete preconditioning of the AAC, the primary desorption is assumed to start from $90 \% \mathrm{RH}$. The actual impact of this estimated retention curve should not be exaggerated though: a recalculation of the dynamic storage coefficients with the main adsorption retention curve instead results in a tiny drop of the $\mathrm{T}$ values, without influencing their order of magnitude however.

\section{Discussion}

The simultaneous measurement of local moisture contents and relative humidities over time during the drying and ad-/desorption of $\mathrm{CaSi}$ and $\mathrm{AAC}$ gave dynamic moisture retention curves for both materials. Comparison with the respective static retention curves showed clear deviations, a sign of the occurrence of dynamic effects during the drying and ad-/desorption processes. This reveals that moisture transfer in building materials, akin to moisture transfer in soils, is not free of dynamic effects.

The general observations show that dynamic effects yield higher moisture retention for desaturation processes (drying \& desorption) - a lower moisture content in comparison to the static curve at the same capillary pressure -, whereas lower retention is observed for saturation processes (adsorption). This agrees with earlier research on dynamic effects [11]-[22]. The translation to dynamic storage factors gives $\mathrm{T}$ values of around $10^{12}$ to $10^{14} \mathrm{~kg} /(\mathrm{m} \cdot \mathrm{s})$ for drying and $10^{14}$ to $10^{16} \mathrm{~kg} /(\mathrm{m} \cdot \mathrm{s})$ for ad-/desorption; Hassanizadeh et al. [14] obtained t values going from $10^{3}$ to $10^{7} \mathrm{~kg} /(\mathrm{m} \cdot \mathrm{s})$ from soil in-/outflow measurements. The (far) higher values obtained 
Postprint: Janssen H, Scheffler GA, Plagge R. 2016. Experimental study of dynamic effects in moisture transfer in building materials, International Journal of Heat and Mass Transfer, 98: 141-149.

for building materials result from the relatively lower (de)saturation rates and relatively larger deviations between dynamic and static capillary pressures. Based on the data from [14], the orders of magnitude for typical (de)saturation rates and for common differences between dynamic and static capillary pressures during soil in-/outflow experiments amount to respectively $0.001 / \mathrm{s}$ and $1000 \mathrm{~Pa}$. In our drying and ad-/desorption tests, on the other hand, these orders of magnitude are $10^{-5}$ to $10^{-8} / \mathrm{s}$ and $10^{5}$ to $10^{8} \mathrm{~Pa}$ respectively. Consequently far larger $\mathrm{T}$ values are obtained. These comparatively large values are in line with Stauffer's empirical relation, which predicts large $(r)$ t for materials with high entry pressure and low permeability, which is typical for building materials (relative to soils).

These findings may have far-reaching consequences, for moisture transfer in building materials in particular and in porous media in general. Both tests are often applied when characterising the moisture permeability of building materials, by fitting numerical simulations to experimental results [22],[33]-[35]. An intrinsic deviation between simulations applying the static theory and measurements affected by dynamic effects flaws the reliability of the resulting material properties and as such all simulations using these. And even if only stationary tests are used for hygric property characterisation, most assessments of moisture transfer in building materials target transient processes, the simulation of which would similarly be faulty if dynamic effects are neglected. And given that the drying and ad-/desorption processes studied here are dominant features in many instances of moisture transfer in porous media [3][8], our findings for building materials in particular may have ramifications for porous media in general. Further research is however required in that respect.

\section{CONCLUSION}

In relation to moisture storage in porous materials, it is often assumed that the process dynamics do not affect the moisture retention, or in other words, it is commonly presumed that the relation between moisture potential and moisture content is not disturbed by dynamic effects. There is however mounting evidence that this notion is incorrect: various experimental, theoretical and numerical studies [11]-[22] demonstrate that the moisture retention is affected by the (de)saturation rates of the moisture transfer processes involved.

Virtually all of the currently available evidence on dynamic effects for moisture transfer stems from imbibition and drainage experiments on soils. With respect to many other porous media, these tests concern rather permeable materials with relatively dominant liquid transport at comparatively large (de)saturation rates. Generally though, moisture transfer in porous media - among which building materials - involves less permeable materials, with mixed liquidvapour transfer, at lower (de)saturation rates [3]-[8]. The present knowledge on dynamic effects may thus not be directly transferable to moisture transfer in porous media on the whole, and dedicated further research is consequently needed.

This article has responded to that need, by reporting on an experimental investigation of the occurrence of dynamic effects on moisture transfer in building materials. In the investigation drying and ad-/desorption tests were executed on two building materials, during which moisture contents and moisture potentials were measured simultaneously. These were transformed into dynamic retention relations and dynamic storage coefficients, which both distinctly demonstrated that moisture transfer in building materials, similar to moisture transfer in soils, is not free of dynamic effects.

Our findings imply that the widely accepted static theory for moisture storage in porous media is not generally valid and should be corrected for the occurrences of dynamic effects. In light of these drying and ad-/desorption processes being dominant features in very many instances of moisture transfer in porous media [3]-[8], the ramifications of these findings may exceed the field of building materials in particular, and concern the area of porous media in general. Further research is however required in that respect. 
Postprint: Janssen H, Scheffler GA, Plagge R. 2016. Experimental study of dynamic effects in moisture transfer in building materials, International Journal of Heat and Mass Transfer, 98: 141-149.

doi: 10.1016/j.ijheatmasstransfer.2016.03.031

\section{ACKNOWLEDGEMENTS}

The second author wishes to acknowledge the financial supports from the Danish Research Council for Technology and Production (grant nr. 274-07-039) and the DTU Hans Christian Ørsted postdoc fund. The authors also wish to thank Frank Meißner - Franky - for his contributions to the experiments at Dresden University of Technology.

\section{REFERENCES}

[1] Cano-Barrita P.F.dJ., Balcom B.J., Bremner T.W., MacMillan M.B., Langley W.S. 2006. Moisture distribution in drying ordinary and high performance concrete cured in a simulated hot dry climate, Materials and Structures 37: 522-531.

[2] Pruess K., Yabusaki S., Steefel C., Lichtner P. 2002. Fluid flow, heat transfer, and solute transport at nuclear waste storage tanks in the Hanford vadose zone, Vadose Zone Journal 1: 68-88.

[3] Liu H., Nagano K. 2014. Numerical simulation of an open sorption thermal energy storage system using composite sorbents built into a honeycomb structure, International Journal of Heat and Mass Transfer 78: 648-661.

[4] Neves S.F., Campos J.B.L.M., Mayor T.S. 2015. On the determination of parameters required for numerical studies of heat and mass transfer through textiles - Methodologies and experimental procedures, International Journal of Heat and Mass Transfer 81: 272-282.

[5] Shargatov V.A., Il'ichev A.T., Tsypkin G.G. 2015. Dynamics and stability of moving fronts of water evaporation in a porous medium, International Journal of Heat and Mass Transfer 83: 552-561.

[6] Beneš M., Štefan R. 2015. Hygro-thermo-mechanical analysis of spalling in concrete walls at high temperatures as a moving boundary problem, International Journal of Heat and Mass Transfer 85: 110-134.

[7] Pečenko R., Svensson S., Hozjan T. 2015. Modelling heat and moisture transfer in timber exposed to fire, International Journal of Heat and Mass Transfer 87: 598-605.

[8] Bezerra C.V., Meller da Silva L.H., Corrêa D.F., Rodrigues A.M.C. 2015. A modeling study for moisture diffusivities and moisture transfer coefficients in drying of passion fruit peel, International Journal of Heat and Mass Transfer 85: 750-755.

[9] Marshall J.S., Fuhrmann A.P. 2015. Effect of rainfall transients on thermal and moisture exposure of underground electric cables, International Journal of Heat and Mass Transfer 80: 660-672.

[10] Wu D., Lai Y., Zhang M. 2015. Heat and mass transfer effects of ice growth mechanisms in a fully saturated soil, International Journal of Heat and Mass Transfer 86: 699-709.

[11] Topp G.C., Klute A., Peters D.B. 1967. Comparison of water content-pressure head data obtained by equilibrium, steady-state, and unsteady-state methods. Soil Science Society of America Proceedings 31: 312-314.

[12] Smiles D.E., Vauchaud G., Vauclin M. 1971. A test of the uniqueness of soil moisture characteristic during transient, non-hysteretic flow of water in a rigid soil. Soil Science Society of America Proceedings 35: 534-539.

[13] Wana-Etyem C. 1982. Static and dynamic water content pressure head relations of porous media. Phd-thesis, Colorado State University, Fort Collins, Colorado, USA.

[14] Hassanizadeh S.M., Celia M.A., Dahle H.K. 2002. Dynamic effects in the capillary pressure-saturation relationship and its impacts on unsaturated flow. Vadose Zone Journal 1: 38-57.

[15] Mumford K.M., O'Carroll D.M. 2010. Drainage under non-equilibrium conditions: exploring wettability and dynamic contact angle effects using bundle-of-tubes simulations. Vadose Zone Journal 10: 1162-1172.

[16] Joekar-Niasar, V., Hassanizadeh, S.M. 2011. Effect of fluids properties on non-equilibrium capillarity effects: Dynamic pore-network modelling. International Journal of Multiphase Flow 37: 198-214. 
Postprint: Janssen H, Scheffler GA, Plagge R. 2016. Experimental study of dynamic effects in moisture transfer in building materials, International Journal of Heat and Mass Transfer, 98: 141-149.

[17] Schultze B., Ippisch O., Huwe B., Durner W. 1999. Dynamic non-equilibrium during unsaturated water flow. In M.Th. van Genuchten et al. (ed.) Proc. Int'l. Workshop, Characterization and Measurement of the Hydraulic Properties of Unsaturated Porous Media. University of California, Riverside, California, USA, p. 877-892..

[18] O'Carroll D.M., Mumford K.G., Abriola L.M., Gerhard J.I. 2010. Influence of wettability variations on dynamic effects in capillary pressure. Water Resources Research 46: W08505.

[19] Hassanizadeh S.M., Gray W.G. 1993. Toward an improved description of the physics of two-phase flow. Advances in Water Resources 16:53-67.

[20] Juanes R. 2009. Nonequilibrium effects in models of three-phase flow in porous media. Advances in Water Resources 31: 661-673.

[21] Tian S., Lei G., He S., Yang S. 2012. Dynamic effect of capillary pressure in low permeability reservoirs, Petroleum Exploration and Development 39: 405-411.

[22] Scheffler G.A. 2008. Validation of hygrothermal material modelling under consideration of the hysteresis of moisture storage. PhD thesis, Dresden University of Technology, Dresden, Germany.

[23] Pease B.J., Scheffler G.A., Janssen H. 2012. Monitoring moisture movements in building materials using $X$-ray attenuation: Influence of beam-hardening of polychromatic $X$ ray photon beams. Construction and Building Materials 36: 419-429.

[24] Roels S., Carmeliet J. 2006. Analysis of moisture flow in porous materials using microfocus Xray radiography. International Journal of Heat and Mass Transfer 49: 47624772.

[25] Scheffler G.A., Plagge R. 2011. Application of instantaneous profile measurement of moisture content and moisture potential in porous materials. Materials \& Structures 44: 1517-1536.

[26] Malicki M.A., Skierucha W.M. 1989. A manually controlled TDR soil moisture meter operating with 300 ps rise-time needle pulse. Irrigation Science 10: 153-163.

[27] Pavlik Z., Pavlíková M., Fiala L., Černý R, Sobczuk H, Suchorab Z. 2007. Application of time-domain reflectometry method for measuring moisture content in porous building materials. Trends in Applied Sciences Research 2: 188-200.

[28] Cleveland W.S. 1979. Robust locally weighted regression and smoothing scatterplots. Journal of the American Statistical Association 74: 829-836.

[29] Cleveland W.S., Devlin S.J. 1988, Locally weighted regression: An approach to regression analysis by local fitting. Journal of the American Statistical Association 83: 596-610.

[30] Peltier, J. 2009. LOESS smoothing in Excel. http://peltiertech.com/WordPress/loesssmoothing-in-excel/, last accessed on April 102015.

[31] Funk M. 2012. Hysteresis der Feuchtespeicherung in porösen Materialien. PhD thesis, Dresden University of Technology, Dresden, Germany.

[32] Koronthalyova O. 2010. Water vapour sorption hysteresis of autoclaved aerated concrete and burnt clay brick. In Proceedings of the $1^{\text {st }}$ Central European Symposium on Building Physics, September 13-15 2010, Cracow, Poland.

[33] Carmeliet J., Roels S. 2001. Determination of the isothermal moisture transport properties of porous building materials. Journal of Thermal Envelope and Building Science 24: 183-210.

[34] van Schijndel A.W.M. 2009. The exploration of an inverse problem technique to obtain material properties of a building construction. In Proceedings of $4^{\text {th }}$ International Building Physics Conference, June 15-18 2009, Istanbul, Turkey.

[35] Scheffler G.A., Plagge R. 2010. A whole range hygric material model: modelling liquid and vapour transport properties in porous media. International Journal of Heat and Mass Transfer 53: 286-296.

[36] Stauffer F. 1978. Time dependence of the relations between capillary pressure, water content and conductivity during drainage of porous media. In Proceedings of IAHR Symposium on Scale Effects in Porous Media, August 29-September 1 1978, Thessaloniki, Greece. 